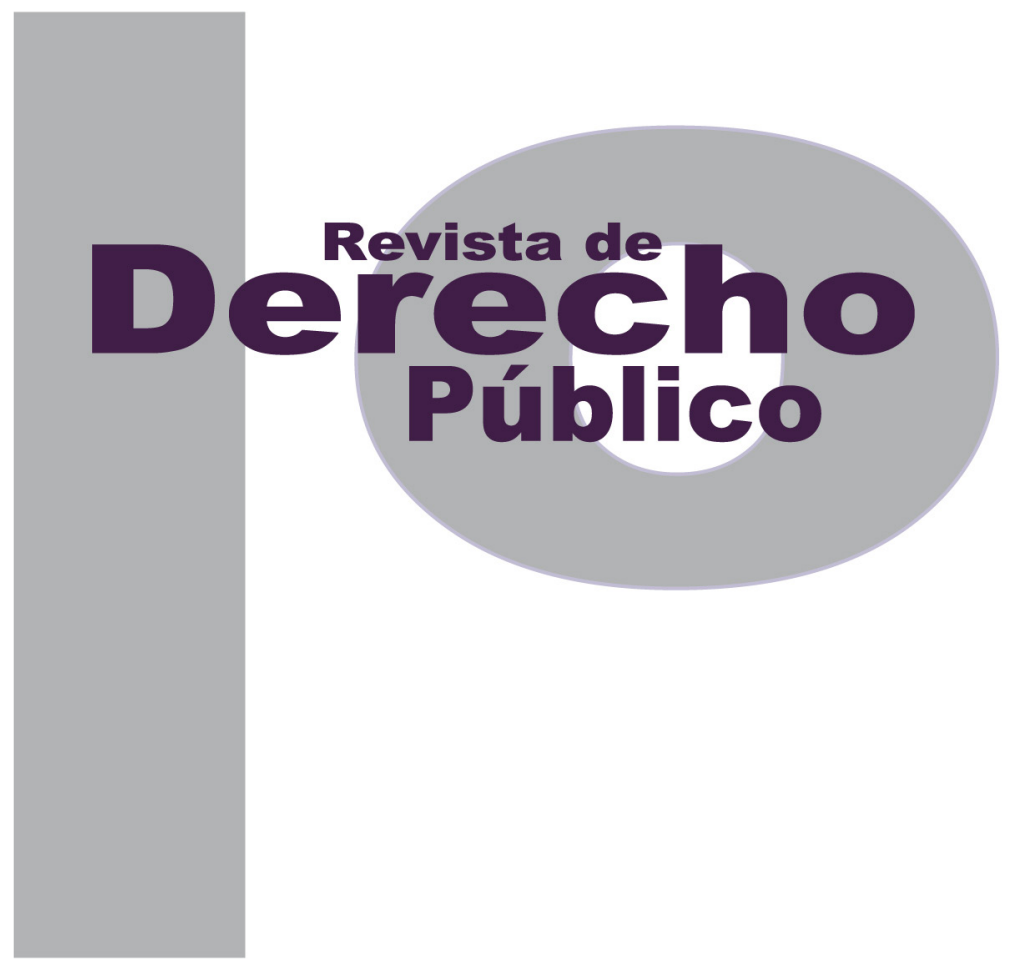

\title{
ANÁLISIS CONCEPTUAL Y PRÁCTICAS DISCURSIVAS DE LOS PARTICIPANTES EN EL SISTEMA JURÍDICO
}

\author{
Dúber ARMANDo Celis Vela
}

Artículo de reflexión

DOI: http://dx.doi.org/10.15425/redepub.36.2016.16

Universidad de los Andes

Facultad de Derecho

Rev. derecho publico No. 36

enero - junio de 2016. e-ISSN 1909-7778 


\section{Análisis conceptual y prácticas discursivas de los participantes en el sistema jurídico Resumen}

Este trabajo caracteriza el papel de la filosofía en el análisis de los discursos jurídicos. Pretende explicar el uso de los conceptos en la argumentación de los participantes en el derecho. Las discrepancias entre participantes justifican la presencia de discursos jurídicos, los cuales envuelven una pretensión de corrección. La existencia de pretensiones normativas en el discurso jurídico exige que el análisis conceptual esté vinculado con la filosofía hermenéutica, con el fin de explicar prácticas de creación, interpretación y aplicación del derecho. La reconstrucción de los conceptos jurídicos depende de los discursos porque los enunciados normativos son interpretados según pretensiones de corrección jurídica, económica o política. Así se determina la existencia, alcance y justificación de los derechos en el discurso de los participantes.

Palabras clave: discursos jurídicos, análisis conceptual, hermenéutica, práctica jurídica, participantes, pretensión de corrección.

\section{Conceptual analysis and discursive practices of legal actors}

Abstract

This paper locates philosophy in the analysis of legal discourses. It aims to explain the uses of concepts in the argumentation of legal actors. Discrepancies between actors justify the existence of legal discourses, which involve a pretension of correction. These normative pretensions in legal discourse require the linking of legal discourse to hermeneutical philosophy to explain the practices of creation, interpretation, and adjudication of law. The reconstruction of legal concepts is given by discourses, since normative statements are interpreted with an aim of legal, economic, or political correction. In this way, the existence, scope and justification of rights in the discourse of legal actors are determined.

Key words: Legal discourses, conceptual analysis, hermeneutics, legal practice, participants, pretensions of correction.

\section{Análise conceitual e práticas discursivas dos participantes no sistema jurídico}

\section{Resumo}

Este trabalho caracteriza o papel da filosofia na análise dos discursos jurídicos. Pretende explicar o uso dos conceitos na argumentação dos participantes no direito. As discrepâncias entre participantes justificam a presença de discursos jurídicos, os quais envolvem uma pretensão de correção. A existência de pretensões normativas no discurso jurídico exige que a análise conceitual esteja vinculada com a filosofia hermenêutica com o fim de explicar práticas de criação, interpretação e aplicação do direito. A reconstrução dos conceitos jurídicos depende dos discursos porque os enunciados normativos são interpretados segundo pretensões de correção jurídica, econômica ou política. Assim se determina a existência, alcance e justificação dos direitos no discurso dos participantes.

Palavras-chave: discursos jurídicos, análise conceitual, hermenêutica, prática jurídica, participantes, pretensão de correção. 


\title{
Análisis conceptual y prácticas discursivas de los participantes en el sistema jurídico*
}

\author{
DÚBER ARMANDO CELIS VELA**
}

\begin{abstract}
SUMARIO
Introducción - I. ANÁLISIS CONCEPTUAL Y PRÁCTICAS DISCURSIVAS EN EL DERECHO - A. Encuentros y desencuentros en las tradiciones analíticas y hermenéuticas de la filosofía del derecho - B. Críticas y limitaciones del análisis conceptual como modo de aproximación al derecho - II. EL ANÁLISIS CONCEPTUAL Y LA POSICIÓN DE LOS PARTICIPANTES. EL DISCURSO JURÍDICO COMO OBJETO DE ANÁLISIS FILOSÓFICO - III. DISCURSOS DOGMÁTICOS Y JUSTIFICACIÓN FÁCTICONORMATIVA DE LOS DERECHOS SOCIALES - IV. CONCLUSIONES - Referencias.
\end{abstract}

* Cómo citar este artículo: Celis Vela, D. A. (Junio, 2016). Análisis conceptual y prácticas discursivas de los participantes en el sistema jurídico. Revista de Derecho Público, (36). Universidad de los Andes (Colombia). DOI: http://dx.doi.org/10.15425/ redepub.36.2016.16

** Magíster en Derecho y abogado de la Universidad de Antioquia; licenciado en Filosofía, de la Universidad Pontificia Bolivariana. Profesor de cátedra de la Universidad de Antioquia, integrante del grupo de investigación Saber, Poder y Derecho, e investigador de la línea Filosofía del Derecho Constitucional. Correo: duber.celis@udea.edu.co

Artículo de investigación resultado del proyecto "Uso discursivo de los derechos sociales en Colombia y las limitaciones fácticas de su eficacia normativa", adscrito a la línea de investigación Filosofía del Derecho Constitucional del grupo Saber, Poder y Derecho de la Facultad de Derecho y Ciencias Políticas de la Universidad de Antioquia, el cual fue asesorado por el profesor Roberth Uribe Álvarez. 
Introducción

En la teoría jurídica contemporánea se ha buscado adecuar el derecho a pautas formales y sustantivas de racionalidad. Entre las tareas dominantes conviene resaltar la formulación de conceptos teóricos para reconocer sus elementos constitutivos y explicar las relaciones que determinan su funcionamiento. En el positivismo jurídico se ha analizado, entre otros, el concepto "sistema normativo" con el fin de identificar sus propiedades formales, entre las cuales han sido subrayadas la coherencia interna de los enunciados normativos, la eliminación de las antinomias y la independencia de las disposiciones legales (Alchourrón y Bulygin, 2002, p. 22). La sistematización del derecho, en términos de coherencia y completitud, es un propósito asumido tradicionalmente por el legislador en su labor codificadora y por el dogmático en su función de hacer inteligibles las disposiciones jurídicas. Sin embargo, estos intentos de sistematización envuelven problemas no resueltos en la teoría y la dogmática jurídicas, con independencia de que sean considerados como ideales que cualquier actividad teórica o práctica sobre el derecho deba alcanzar.

Si bien la construcción de arquitecturas conceptuales es fundamental para el desarrollo de cualquier disciplina o ciencia, estas no constituyen explicaciones autorreferentes, dado que agotan su significado en las convenciones que las contienen (Nino, 1994, p. 30). El uso de los conceptos, además de aspectos semánticos, está relacionado con prácticas discursivas que llevan a cabo los participantes en una actividad.
El análisis de conceptos jurídicos expresa la existencia de discrepancias teóricas y normativas entre los participantes en la práctica jurídica. Los desacuerdos jurídicos no son un hecho irrelevante al momento de construir o analizar los conceptos que describan o justifiquen el quehacer de los participantes en el derecho.

El problema de los desacuerdos ha despertado interés académico a partir del segundo debate originado en la crítica de Ronald Dworkin a $\mathrm{H}$. L. A. Hart (Shapiro, 2007, p. 3). El concepto de sistema jurídico hartiano está fundamentado en una práctica convergente de identificación de normas (Hart, 1998, p. 125) sin considerar si, en tal apreciación, es posible aceptar desacuerdos entre quienes participan en dicha práctica. Por esta razón, Dworkin (1986, p. 13) le reprocha al positivismo hartiano el hecho de no dar cuenta de los desacuerdos teóricos, y pretende resolver este problema con la polémica propuesta de una interpretación constructiva destinada a convertirse en el mejor ejemplo de práctica posible (Dworkin, 1986, p. 52). Esta idea ha hecho pensar que el derecho no es un ejercicio basado en hechos sociales sino una actividad argumentativa que tiende a la corrección. Si bien Dworkin resaltó que el desacuerdo está en la base del derecho, paradójicamente buscó eliminarlo como resultado, pues la idea de la respuesta correcta deja de lado las tensiones normativas que pueden explicar las prácticas de los participantes en el sistema jurídico.

En términos analíticos, es posible distinguir dos clases de desacuerdos: internos y externos. 
Los primeros se producen entre quienes aplican y deciden qué es el derecho, y, los segundos, entre quienes se aproximan teóricamente o dicen cómo debería ser (Luque Sánchez y Ratti, 2012, p. 24). Los desacuerdos externos no solo tienen lugar entre juristas, pues el carácter social del derecho permite que en ellos participen economistas, filósofos políticos y morales, sociólogos y politólogos, entre otros. Estas diferencias acerca de qué es el derecho válido pueden representar desacuerdos genuinos, pues se trata de desencuentros normativos, de creencias o sencillamente de actitudes que expresan adhesión o rechazo a determinado estándar de derecho. Sin embargo, en este panorama se puede considerar que, en muchos casos, los participantes no entienden lo mismo cuando hablan de derecho, es decir, no tienen desacuerdos sobre el mismo objeto aunque recurran a los mismos conceptos.

La ausencia de criterios para determinar la corrección de las posiciones adoptadas es un hecho que genera perplejidad y desconcierto entre los participantes. Participante es quien argumenta dentro de un sistema jurídico a favor de lo que está ordenado, prohibido o permitido (Alexy, 2004, p. 41). Estas exigencias normativas conducen a la formación de discursos que consisten en prácticas argumentativas usadas para satisfacer pretensiones en un sis- tema jurídico dado. ${ }^{1}$ Esta situación ha renovado el interés por la metodología y el estatus del conocimiento dogmático y teórico sobre el derecho, al punto que sus enfoques se han ampliado significativamente. Las disputas recientes sobre el derecho no solo han versado sobre problemas sustantivos sino conceptuales, e involucran lo que una teoría del derecho se propone y puede hacer (Raz, 2007, p. 113; Bix, 2006). Así, el derecho parece ser una extraña combinación entre estabilidad y contingencia, de un lado; y entre voluntad y justificación, de otro. Tal vez este hecho explique por qué las teorías están destinadas a ser parciales y relativas. Por esta razón, una forma de entender las prácticas jurídicas es a través de la reconstrucción de conceptos jurídicos en disputa.

Las discrepancias entre participantes no solo se presentan a nivel teórico, es decir, cuando tratan de señalar la "naturaleza" del derecho o sus componentes. También tienen lugar en la interpretación de textos normativos que cumplen una función determinante en las democracias contemporáneas, como lo es la Constitución. El nivel de abstracción y la condición valorativa de muchas de las disposiciones jurídicas de la Carta Magna han generado tensiones y disputas no menos complejas que ininteligibles. Este es el caso especial de los Ilamados derechos sociales, ${ }^{2}$ en el cual abundan

1. Alexy (2004, p. 40) considera que la pretensión de corrección es un elemento necesario del concepto de derecho, y ha utilizado este concepto para establecer relaciones entre derecho y moral. A continuación se usará el concepto pretensión de corrección en sentido amplio, es decir, para señalar la posición que adopta un participante en el sistema jurídico, la cual no envuelve una pretensión moral sino política, económica o pragmática.

2. Los derechos sociales son disposiciones jurídicas que regulan las necesidades básicas de los ciudadanos. Dichas necesidades se agrupan en torno a programas de seguridad social para promover una garantía económica mínima, red de servicios 
las discrepancias metodológicas, axiológicomorales, antropológicas, económicas y políticas. Los participantes en este debate parecen defender las mismas instituciones jurídicas o conceptos; sin embargo, muchas de sus posiciones teóricas son irreconciliables.

Cómo pueda explicarse una situación de esta naturaleza es uno de los problemas planteados en este texto con el propósito de aclarar la manera como funciona la práctica jurídica en materia de derechos sociales. El derecho no es independiente de los comportamientos $y$ actitudes de autoridades $y$ destinatarios, por esta razón, no puede concebirse como una entidad puramente objetiva (Sastre, 2001, p. 585). Tal vez esta circunstancia justifique por qué el derecho no es una práctica social acabada sino en construcción, pues las discrepancias entre los participantes tienden a persistir; sin embargo, es necesario identificar criterios teóricos para comprender el sentido o la lógica que subyace tras los distintos usos discursivos de los conceptos en el derecho. Para que este análisis no sea otro discurso más, el problema será abordado desde una perspectiva filosófica, con el fin de proporcionar una explicación general, o por lo menos, formular criterios de orientación conceptual en lo que parece ser una babel de lenguas incomprensibles.

El propósito del primer aparte es caracterizar el papel de la filosofía frente al análisis de los discursos jurídicos en general. Una razón que justifica este objetivo es la necesidad de encontrar una explicación a la manera como funcionan los conceptos jurídicos. Aunque es posible asignarle diversas funciones a la actividad filosófica sobre el derecho, resulta indispensable hacer explícitos sus presupuestos teóricos y metodológicos para llevar a cabo los objetivos trazados. ${ }^{3}$ Esta exigencia supone varias apreciaciones metafilosóficas y comporta un análisis específico de las entidades, sujetos e interacciones que hacen parte del concepto de derecho, entre las cuales se encuentra el discurso jurídico.

Para llevar a término esta ruta inicial, (1) se hará una reconstrucción de la actividad filosófica en las concepciones del derecho más representativas de la tradición analítica; (2) se desarrollará un concepto de discurso jurídico como categoría que incluye prácticas definitorias, descriptivas y prescriptivas de participantes en un sistema jurídico y se determinará su

sociales y regulación de determinadas relaciones (Noguera, 2010, p. 19). En esta investigación la expresión "derechos sociales" será usada como equivalente de "derechos económicos, sociales y culturales", la cual es más frecuente en el discurso del derecho internacional por razones formales, pues así son llamados en el Pacto Internacional de Derecho Económicos, Sociales y Culturales.

3. Las expresiones filosofía del derecho y teoría del derecho se usarán como equivalentes. Al respecto, Manuel Atienza (2001, p. 103) ha señalado que los autores analíticos prefieren usar la expresión teoría del derecho quizá para dar a entender que sus preocupaciones son más de orden metodológico y conceptual que valorativo. Los intentos de diferenciación de ambas etiquetas no son lo suficientemente claros para atribuir objetos y métodos diferentes. Por tanto, ambos conceptos refieren la misma actividad. A diferencia de esta posición, autores como Bobbio (2012, p. XI) se esfuerzan por diferenciar entre teoría general del derecho y filosofía del derecho. 
alcance como referente para la comprensión y justificación en procesos de creación, interpretación y aplicación del derecho positivo; finalmente, (3) se caracterizarán algunos discursos de los derechos sociales como caso particular de análisis en filosofía del derecho constitucional y se plantearán algunas conclusiones generales sobre el análisis de los discursos en el derecho.

\section{ANÁLISIS CONCEPTUAL Y PRÁCTICAS DISCURSIVAS EN EL DERECHO}

La variedad de tipos y propósitos que se identifican y asignan a la filosofía del derecho es tan amplia que un ejercicio de reconstrucción racional, por más general y abstracto que prometa ser, puede incurrir en reduccionismos y simplificaciones que desdibujan la complejidad de las orientaciones existentes. A fin de preservar la pluralidad teórica de los resultados originados en la relación estrecha entre filosofía analítica y derecho, se hará una reconstrucción de los presupuestos metafilosóficos básicos que han determinado la actividad filosófica. Con mayor razón si se tiene en cuenta que intensos debates y controversias han enriquecido y dinamizado la labor iusteórica, al punto que los desacuerdos se han convertido en una condición fundamental para el desarrollo del pensamiento jurídico. ${ }^{4}$ Justo este aspecto es objeto de análisis conceptual y metodológico en esta investigación, para caracterizar las formas y las intenciones conceptuales del análisis filosófico en la teoría del derecho. Por tanto, no se hará una descripción de las corrientes que conforman el pensamiento iusfilosófico contemporáneo, pues la función de organizar el universo de concepciones corresponde al historiador de la filosofía del derecho.

La reconstrucción racional versará sobre el análisis conceptual y la hermenéutica jurídica como aspectos específicos de la iusteoría contemporánea, de ninguna manera se pretende una reconstrucción de la filosofía analítica y hermenéutica durante el siglo XX. En efecto, se tratará de describir en qué consiste el análisis conceptual del derecho, y cuáles son sus presupuestos, propósitos y límites en el marco de teorías positivistas y no positivistas del derecho. ${ }^{5}$ En suma, se hará una revisión metodológica para dar cuenta de los elementos constitutivos de la práctica jurídica. Las críticas y limitaciones a este modo de aproximación al derecho buscan

4. Una clasificación de la filosofía del derecho en atención a los resultados sería interminable, pues la clasificación de estos varía según el problema abordado. Incluso las dificultades trascienden hasta las formas de denominación de tales teorías, pues en términos generales se habla de iusnaturalismo; neoiusnaturalismo; positivismo metodológico, teórico, ideológico, incluyente, excluyente, normativo o ético; no positivismo, antipositivismo, postpositivismo, entre otros. Para evadir tan compleja tarea de caracterización y evitar las discusiones semánticas se hará una reconstrucción metateórica, en razón de lo cual se determinará la actividad filosófica sobre el derecho.

5. En principio, estas etiquetas no arrojan claridad sobre el contenido específico de lo que será objeto de análisis, pues las tipologías que existen no son menores en relación con la filosofía del derecho. Sin embargo, es posible identificar algunas posiciones metateóricas compartidas entre quienes se llaman positivistas y no positivistas. Algunas de estas posiciones compartidas han terminado por introducirse en la práctica de jueces y tribunales, lo cual constituye un elemento necesario para comprender las prácticas de los participantes en un sistema jurídico. 
la articulación del análisis conceptual con las posiciones que los participantes desempeñan en un sistema jurídico. Se propone que el análisis conceptual, orientado al análisis de prácticas discursivas como actividades propias de participantes, proporciona criterios para comprender las prácticas de creación, interpretación, aplicación y obediencia del derecho.

\section{A. Encuentros y desencuentros en las tradiciones analíticas y hermenéuticas de la filosofía del derecho}

El giro lingüístico ${ }^{6}$ facilitó la consolidación de dos tradiciones filosóficas en Occidente: las fiIosofías analítica y hermenéutica. Aunque en muchos aspectos tienen orientaciones diferentes, incluso irreconciliables, es necesario admitir que ambas concepciones reivindican el lenguaje como una condición de posibilidad para el conocimiento, el pensamiento y la comunicación. ${ }^{7}$ Sin embargo, la referencia al lenguaje como tal no es una razón suficiente para formular relaciones conceptuales o metodológicas entre las dos corrientes. En su fase inicial, el movimiento analítico ${ }^{8}$ se centró en problemas lógicos y semánticos con propósitos de formalización lingüística. Esta concepción representa una tendencia de análisis de carácter formal y universalista centrada en la construcción de una sintaxis lógica de tipo ideal (Russell, 2003; Wittgenstein, 1989; Carnap, 1963). La formulación de relaciones unívocas entre proposiciones y hechos adoptó presupuestos que, de cierta forma, terminaron por marginar los problemas hermenéuticos.

Si bien el análisis lógico desempeñó una función primordial para abordar problemas epistemológicos y para subrayar el carácter avalorativo de toda actividad cognoscitiva, no constituyó la única forma de entender la actividad filosófica en el movimiento analítico. Adoptar esta posición como exclusiva implica profundizar el desencuentro entre hermenéutica y análisis filosófico, pues en este aspecto la filosofía hermenéutica es antipositivista y anticientificista dado que no acepta como único criterio de verdad la confirmación o verificación de los hechos. No significa lo anterior que en una concepción hermenéutica el conocimiento sea

6. Denominación usada por Richard Rorty (1998, p. 45) para hacer una descripción de esta filosofía y cuestionarla en sus presupuestos metafilosóficos. Habermas (2002) considera que el giro lingüístico representa un nuevo paradigma filosófico que deja de lado la filosofía de la conciencia para privilegiar las relaciones del lenguaje con el mundo. Pese a la diferencia de concepciones, ambos autores enfatizan el cambio de orientación en la filosofía por el decidido interés por el lenguaje.

7. Una concepción más amplia sobre el lenguaje puede encontrarse en la tradición hermenéutica por cuanto esta lo considera el medio universal en el que se realiza la comprensión (Gadamer, 2006, p. 467). Debe tenerse en cuenta que la hermenéutica se propone aportar un fundamento epistemológico a las ciencias del espíritu y se hace cargo de la comprensión como algo más que una forma de conocimiento o reglas metodológicas. La interpretación se basa en precomprensiones que van siendo corregidas. Esta concepción puede explicar la continua reconstrucción que realizan los participantes de sus pretensiones en el marco de exigencias jurídicas.

8. Esta expresión designa las diversas corrientes de pensamiento conocidas como filosofía analítica. De ninguna manera constituye una unificación de teorías o métodos, pues tal empresa es imposible debido a las distancias teóricas que existen entre los filósofos de orientación analítica (Gracia, Rabossi, Villanueva y Dascal, 1985, p. 11). 
arbitrario y esté privado de criterios de objetividad. Por el contrario, representa otra perspectiva de la epistemología jurídica que recurre a un método normativo-valorativo y reflexiona sobre problemas de transmisión y desciframiento de sentidos (Vega, 2009, p. 391). La comprensión o la interpretación son actividades regidas por criterios objetivos que se inscriben en el contexto de una tradición. La interpretación no puede verse en forma atomista y lineal, puesto que es una actividad circular (círculo hermenéutico) en la que se producen una serie de interacciones entre precomprensión y texto, parte y todo, norma y hecho (Atienza, 2001, p. 106).

En la segunda mitad del siglo XX, al interior del movimiento analítico, se produjo una suerte de giro pragmático que reconoció las múltiples tareas y funciones del lenguaje, las cuales envuelven tanto dependencias contextuales como equivocidad de significados. El análisis filosófico se ocupó de señalar diferencias y comprender los usos de los conceptos en el lenguaje ordinario. Esta nueva orientación del pensamiento analítico, también derivada de Wittgenstein (1988), permitió tomar distancia de la formalización y hacer énfasis en los lenguajes naturales. Strawson (1997, p. 49) asume el análisis conceptual como la tarea de explicar el bagaje conceptual adquirido en la práctica sin enunciar la teoría de la práctica misma. Así se puede describir y explicar el uso de estructuras de pensamiento para establecer conexiones sistemáticas. En este escenario, la determinación del significa- do permite acudir a los criterios desarrollados por la filosofía hermenéutica, los cuales habían sido neutralizados por la propuesta del lenguaje ideal, impulsada por la primera generación de filósofos analíticos.

La elección de presupuestos metateóricos imprime un carácter específico al análisis conceptual y determina la posibilidad de incorporar elementos hermenéuticos en el análisis filosófico. Aunque dichas tendencias se refieren a aspectos distintos del lenguaje, en tanto actividades o prácticas sociales, puede sostenerse que están relacionadas, pues el filósofo analítico considera que los elementos últimos del lenguaje son los enunciados y las proposiciones, mientras que el filósofo hermenéutico considera al discurso en cuanto situación de lenguaje en la que se realiza la comprensión (Atienza, 2001, pp. 107-108). Las conexiones entre lenguaje y discurso pueden constituir presupuestos conceptuales o metodológicos que redundan en más elementos para la comprensión de las prácticas sociales y, en particular, de las jurídicas. Hermenéutica y filosofía analítica son formas complementarias del giro lingüístico (Habermas, 2002, p. 66), pues una es tan poco prescindible como la otra en la discusión iusteórica contemporánea (Kaufmann, 1999, p. 88).

La naturaleza de la filosofía y la concepción sobre los problemas filosóficos cambiaron de orientación a raíz de las posiciones metafilosóficas adoptadas en el movimiento analítico. ${ }^{9} \mathrm{Al}$

9. Una manera usual de reconstruir la actividad del filósofo analítico consiste en asimilarlo con cierto tipo de terapeuta, que tiene como finalidad curar cierta clase de desorden intelectual que se origina cuando permitimos que los conceptos o pala- 
margen de sus aciertos o desaciertos teóricos, esta forma de concebir la actividad filosófica desafió la capacidad de la filosofía tradicional para dar respuesta a problemas específicos al subrayar (a) la inadecuación conceptual de las preguntas, (b) el carácter poco esclarecedor de los presupuestos lingüísticos y (c) el antagonismo de las teorías filosóficas resultantes. ${ }^{10}$ Como consecuencia, cambió la manera de entender la tarea filosófica, la idea de problemas que debe formular el filósofo y la posibilidad de progreso en filosofía.

Esta manera de comprender la filosofía analítica fue tempranamente criticada por Richard Rorty (1998, p. 116), quien señaló la ausencia de criterios metafilosóficos para disolver los problemas filosóficos y constituir a la filosofía como ciencia estricta sobre la forma lógica del lenguaje ideal o el análisis conceptual del lenguaje ordinario. La formulación de un código para la práctica filosófica de estirpe analítica hace parte de un conjunto de declaraciones metafilosóficas que tales filósofos han disfrazado de necesidad o encierran en una serie de decisiones éticas presentadas como ontología. Aunque tales críticas justificaron la autodenominación "postanalítico", sin duda esta etiqueta no abarca todo el proyecto rortiano, pues este filósofo conservó y practicó los aspectos generales del análisis filosófico. De cierta manera, podría señalarse que Rorty sometió los propósitos de los filósofos analíticos al mismo tribunal usado por estos para someter a los filósofos tradicionales.

La falta de una declaración expresa de los presupuestos metafilosóficos del programa analítico no constituye una razón suficiente para dejar de lado sus preocupaciones y desarrollos metodológicos. Sin duda, la incursión en los asuntos filosóficos adquiere otro matiz si está precedida y acompañada del análisis de sus estructuras lingüísticas. Así las cosas, el campo de trabajo del filósofo analítico no es el mundo sino los esquemas conceptuales necesarios para dar cuenta de él (Navarro y Redondo, 2002, p. 19). La descomposición de nuestro aparato conceptual permite hacer distinciones y explicar las relaciones que se producen con el fin de comprender los rasgos del objeto o la práctica social que lo sustenta. Si el uso de los conceptos puede referir entidades distintas, su elucidación es necesaria para determinar aquello que los hablantes competentes asocian a su empleo (Bouvier, Gaido y Sánchez, 2007, p. 34). Esto no significa que el análisis conceptual agote la actividad filo-

bras se desvinculen de su uso real. El filósofo trata a una pregunta como una enfermedad (Wittgenstein, 1988, p. 255) sin ofrecer doctrinas ni teorías (Wittgenstein, 1989, pp. 4.112). Aunque esta imagen no es compartida por Russell (2003) indica que los analíticos consideran a la filosofía como una actividad que consiste en la elucidación de conceptos que tiene como presupuesto un uso claro y simple del lenguaje.

10. Los problemas clásicos de la filosofía usualmente terminaban justificados desde posiciones teóricas contradictorias como realismo-idealismo, escepticismo-dogmatismo, racionalismo-empirismo, objetivismo-subjetivismo. Esta posición puede explicarse por la orientación metafísica de sus tendencias teóricas, problema que, de cierta manera, había sido anticipado por Kant (2003, p. 231) cuando sugería que el uso ilegítimo de la razón terminaba en paralogismos y antinomias. 
sófica, sino, al contrario, puede ser un presupuesto para la solución o, por lo menos, para la clarificación de los problemas planteados, la identificación de acuerdos o discrepancias y el reconocimiento de las diversas maneras de concebir el mundo.

Si la orientación metafilosófica del pensamiento analítico produjo una transformación radical en la filosofía general durante el siglo XX, no menor ha sido su impacto en la teoría jurídica, pues el derecho moderno se expresa en enunciados lingüísticos que constituyen actos de habla en el sentido advertido por John L. Austin (1982). La idea que el derecho es lenguaje se ha reflejado en las preocupaciones filosóficas y metodológicas de Kelsen, Hart, Ross, Bobbio y ha continuado en los estudios de Von Wright, Alchourrón, Bulygin, Raz, Carrió, Nino y Guastini, entre otros. De cierta manera, se trata de discursos de recepción de las teorías generales sobre el análisis filosófico y la interpretación. Pese a la multiplicidad de sus orientaciones, esta forma de actividad sobre el derecho ha permitido trazar las condiciones de posibilidad para la explicación del concepto de derecho y los sistemas jurídicos actuales.

En la iusteoría contemporánea, el programa metodológico de la filosofía analítica ha tenido diversos usos. Primero, permitió investigar el estatuto epistemológico de la ciencia jurídica y su método, donde la ciencia fue abordada des- de una perspectiva lógico-empirista, toda vez que se hizo énfasis en el carácter descriptivo del conocimiento y se adoptaron métodos propios de la lógica con el fin de hacer un análisis estructural en el derecho (Alchourrón y Bulygin, 2002; Bobbio, 2012, p. 40). ${ }^{11}$ Segundo, se incentivó la construcción de conceptos jurídicos para redefinir o reconstruir el significado de los elementos que integran el fenómeno jurídico. El punto de partida fue el uso de los términos jurídicos, pues ciertos problemas en el derecho no son ajenos a la naturaleza del lenguaje ordinario (Hart, 1998, p. 159). Por tanto, es necesario admitir que las dos principales tendencias de la filosofía analítica fueron recepcionadas en la teoría del derecho y han permitido repensar las relaciones entre lenguaje y realidad jurídica.

El análisis lingüístico en el derecho supuso una reacción crítica frente a las tradiciones metafísico-iusnaturalistas de derecho codificado y benthamianas del common law. Sin embargo, pese a la fecundidad de las metodologías analíticas para la investigación del derecho, algunas de sus tesis sobresalientes en torno al positivismo jurídico o la avaloratividad de la ciencia jurídica han sido sometidas a críticas y revisiones posteriores que, en la actualidad, se conocen con la denominación genérica de postpositivismo jurídico (Calsamiglia, 1998, p. 201). En la agenda de las discusiones iusteóricas recientes se han formulado problemas

11. El uso directo de la lógica para el análisis de la norma jurídica y el ordenamiento ha sido dominante. La lógica deóntica de Von Wright (1979) ocupa, por tanto, un lugar especial por la influencia que ha tenido en teóricos del derecho como Carlos E. Alchourrón y Eugenio Bulygin (2002), entre otros. 
que conectan el análisis conceptual con la interpretación jurídica, sin que se haya tomado conciencia de su utilidad para comprender la práctica del derecho. Las herramientas analíticas y hermenéuticas han sido ingresadas a discusiones relevantes en torno al esclarecimiento de la naturaleza y funcionamiento del derecho, la problematización de las condiciones y funciones de la teoría ${ }^{12}$ y dogmática jurídicas, las relaciones entre derecho y moral, la distinción entre perspectivas de aproximación al derecho ${ }^{13}$ y el desarrollo teórico de la argumentación, entre otras. Todas, discusiones que han estado precedidas y acompañadas de posiciones metaéticas, en muchos casos, irreconciliables. ${ }^{14}$

La filosofía analítica del derecho, pese a los intentos de caracterización, está integrada por una variedad de corrientes con señas de identidad cada vez menores. ${ }^{15}$ Quizá lo único que permanece es el método de análisis como un instrumento teórico que puede ser usado para propósitos distintos (Atienza, 2001, p. 105). Esto no significa que los presupuestos de su aplicación y alcance estén exentos de discrepancias. Pese a las diferencias que existan, dicha herramienta metodológica ha permitido abordar de una manera rigurosa los desafíos filosóficos que representa el derecho, ha insistido en el uso efectivo de los conceptos y ha liberado a la teoría analítica del derecho de cierta inconsciencia metafísica al momento de explicar fenómenos o prácticas sociales.

Aunque el análisis conceptual ha sido subrayado como presupuesto metodológico para formular una explicación sobre la naturaleza del derecho o sus categorías fundamentales (Raz, 1995, p. 132; Alchourrón y Bulygin, 2002; Ale$x y, 2008)$, de ninguna manera puede pensarse que constituya un conjunto de prácticas semejantes o un cuerpo teórico homogéneo. Si bien el análisis filosófico del derecho, como práctica teórica, ha sido dominante en la teoría jurídica reciente, este se ha llevado a cabo con presupuestos y alcance diferentes, no libres de equívocos y ambigüedades. Caracterizar el análisis conceptual en el derecho no es una tarea sencilla, pues ha sido acogido por concepciones

12. Este hecho contrasta con la concepción contemporánea del derecho, pues se ha discutido la posibilidad de perspectivas abstractas y de conjunto sobre el derecho. La idea de una Teoría General del Derecho promovida por Hart (1998, p. XII), sin duda contrastó con la tradición casuística del derecho anglosajón. Ahora, reformas en la enseñanza del derecho buscan una articulación de este con cuestiones prácticas, situación que da lugar a nuevos elementos del fenómeno jurídico como el discurso.

13. Hart (1998, p. 128) introdujo la distinción entre el punto de vista interno y el punto de vista externo para el análisis de la regla de reconocimiento. Pese a que esta distinción ha producido gran rendimiento teórico para la explicación del sistema jurídico, es necesario reconocer que no puede adoptarse un punto de vista externo e interno de manera exclusiva, pues el participante también puede comportarse como un observador (Bulygin, 2009, p. 89).

14. Alexy y Bulygin (2001) son un ejemplo de este renovado debate que conduce a la polémica definición de las relaciones conceptuales entre derecho y moral. En este debate, Bulygin se inclina por una posición escéptica en términos metaéticos.

15. Rabossi (1985, p. 25) ha señalado que entre los filósofos analíticos existen "rasgos de familia" en torno a las relaciones entre filosofía y lenguaje, recelo a la metafísica, positivismo científico y método. Pocas de estas tendencias se mantienen en la actualidad, pues la prevalencia del lenguaje es compartida con la filosofía hermenéutica y no todos se sitúan en una posición crítica frente a la metafísica. 
de orientación iusnaturalista, positivista, realista, antipositivista, no positivista, entre otras. Las herramientas que proporciona la filosofía analítica, en tal virtud, no son ajenas a convicciones sustantivas sobre el derecho y sus prácticas. Esta situación exige hacer una dilucidación sobre el sentido de una investigación conceptual en el derecho. Más que abrirle paso a una cadena metateórica sin límites, se trata de hacer explícitos los presupuestos generales que guían el ejercicio de esta actividad.

De cierta manera, ya se ha realizado una descripción general sobre los propósitos o pretensiones de un ejercicio de análisis conceptual en general y, específicamente, del derecho. Sin embargo, la pregunta sobre qué significa hacer un análisis conceptual es un problema que exige señalar las convicciones metafilosóficas que pueden estar presentes según la noción de concepto implícita. Qué se entienda por conceptos es una cuestión que ha sido objeto de una amplia tradición filosófica en la cual podemos identificar dos grandes tendencias: esencialismo y convencionalismo conceptuales (Nino, 1994, pp. 28-29). El esencialismo, por un lado, considera que los conceptos son el reflejo, concebido como representación mental o significado, de algunas entidades. La noción de los conceptos como retratos de la realidad que se alojan en la mente dio lugar a la posición crítica de la filosofía como espejo de la naturaleza (Rorty, 2001, p. 35). Los conceptos expresan la naturaleza o esencia de entidades que hay en un mundo y que existen fuera de la mente. Tal vez, esta concepción no guarda mucha coherencia con el sentido que tiene el análisis conceptual para la filosofía analítica.

El convencionalismo, por otro lado, sugiere que los conceptos son construcciones individuales o colectivas que dependen de criterios de uso contingentes para clasificar o categorizar entidades. En este contexto, la noción fregeana que considera a los conceptos como sentidos ocupa un lugar fundamental para el surgimiento de la filosofía analítica. El significado en Frege se compone de dos elementos: sentido y referencia. El sentido es un conjunto de propiedades que usan los hablantes para determinar el referente de tal forma que el mismo objeto puede ser visto de maneras diversas, pues a través del conjunto de propiedades descripcionales se llega a los conceptos (Bouvier et al., 2007, pp. 17-18). En esa medida, el análisis de conceptos es análisis de significados.

Si los hablantes asocian diferentes propiedades al objeto en cuestión, esto se traduce en la existencia de varios conceptos (Putnam, 1983). Esta noción impide dar cuenta de los desacuerdos en torno al mismo concepto, ya que si el concepto consiste en propiedades descripcionales una discrepancia en ellas equivale a la posesión de varios conceptos; en consecuencia, las discusiones teóricas serían pseudodiscusiones. Para evitar este problema de identificación y asociación de conceptos, en la teoría analítica se han revitalizado las nociones de esencia y necesidad para determinar la relación entre objetos y conceptos. En estos términos, el análisis conceptual involucra la aserción filosóficamente ambiciosa de que la teoría ha 
capturado aquello que es "esencial" a cierto concepto o práctica, característica "necesaria" para que una práctica o institución justifique la etiqueta en cuestión (Bix, 2006, p. 20).

Las nociones de naturaleza, esencia y necesidad constituyen un problema pendiente de clarificación en la teoría jurídica. Las cosas tienen muchas propiedades, pero al parecer solo algunas de ellas poseen el carácter de esenciales y necesarias, combinación que describe su naturaleza. Cómo identificar la relevancia de estas propiedades para determinar los conceptos depende de principios y posiciones metafilosóficas. La comprensión completa de un concepto, según Raz (2007, p. 51) puede consistir en conocer y entender todos los rasgos necesarios de su objeto, esto es, de aquello de lo que es un concepto. Esta posición sugiere que las propiedades esenciales son independientes del concepto, que existen per se. También se puede considerar que los conceptos tienen dos dimensiones: convencional, vinculada a las reglas socialmente establecidas, e ideal, asociada a la adecuación de los conceptos a los objetos que se refieren (Gaido, 2011, p. 74). Esto quiere decir que los conceptos pretenden ajustarse a lo que son los objetos y, en consecuencia, de acuerdo con Alexy (2007, pp. 90-91), un concepto para ser correcto debe reflejar la naturaleza o esencia de la cosa.

Bulygin (2007, p. 101) cuestiona que las propiedades esenciales o necesarias de una cosa sean independientes del concepto usado para identificarla. Por tanto, es el concepto de una cosa el que determina cuáles son sus propie- dades esenciales y no a la inversa. Esta aguda posición hacer pensar que la determinación de propiedades esenciales independientes de toda conceptualización acarrea no solo realismo ontológico sino esencialismo conceptual. Sin embargo, la posición de Raz (2007, p. 60) se aclara si se tiene en cuenta que, en el caso del derecho, hablar del concepto de derecho es hablar de un concepto en relación con una comunidad cultural. Los conceptos son entidades sociales y sus propiedades esenciales son contingentes al esquema conceptual en cuestión (Gaido, 2011, p. 31). Por tanto, la falta de patrones de corrección externos a la práctica que los constituye distancia a Raz de Alexy y disuelve la presunta discrepancia con Bulygin.

Tanto el aparato conceptual como los objetos referidos existen como realidades sociales, de ahí que el ejercicio de clarificación redunda en una mayor comprensión de las instituciones o en la precisión de los conceptos. El acento está en señalar que el concepto no se agota en lo que el sujeto asocia a él, sino que también es necesaria cierta relación apropiada con este, la cual depende de una convención social. Los conceptos no pueden ser enteramente autorreferentes, pues su significado no se agota con referencia a las convenciones que los contienen (Nino, 1994, p. 30). De esta manera, se evita el esencialismo y se mantiene al convencionalismo en sus justas proporciones.

El análisis conceptual consiste, para la perspectiva esencialista, en un ejercicio epistémico de reconocimiento e identificación de propiedades ontológicas, y para el convencionalismo, en 
el reconocimiento de usos compartidos para determinar qué elementos o significados hacen parte de su correcta aplicación. Una concepción convencionalista del análisis conceptual considera que este consiste en descomponer los elementos lingüísticos para determinar cómo se relacionan e implican entre sí, es decir, para señalar las conexiones que guardan unos conceptos con otros. La elucidación conceptual se ocupa, entonces, de lo que los hablantes asocian al empleo del concepto o hacen cuando lo emplean, es decir, pone el acento en las prácticas lingüísticas pero no se agota en ellas. Esta es la tarea básica de la filosofía.

En términos muy generales, la investigación conceptual, como rasgo sobresaliente de la filosofía analítica del derecho, se ha ocupado en señalar distinciones lógicas y conexiones entre diferentes conceptos (Von Wright, 2010, p. 37). El lugar privilegiado que ha ocupado el análisis conceptual para el acceso y la solución de problemas jurídicos, de cierta manera, ha permitido neutralizar la inclinación sustancialista de la filosofía tradicional. En estos términos, la filosofía del derecho no consiste en desvelar la oculta esencia del fenómeno jurídico sino en esclarecer el aparato conceptual, idear métodos para la ciencia del derecho (Bulygin y Alchourrón, 1991, p. 380) y proporcionar categorías conceptuales para abordar el derecho desde las condiciones de posibilidad de sus enunciados.

Si bien el análisis conceptual aparece como una perspectiva metodológica común a teorías positivistas, realistas, no positivistas o postpositivistas, esto no es contradictorio, pues ya se ha señalado que este es posible realizarlo según compromisos ontológicos y axiológicos diferentes. Las críticas postpositivistas a la teoría formal del derecho, a la concepción avalotativa de la ciencia social y a las visiones metaéticas no cognitivistas han producido paulatinamente una conexión de la filosofía del derecho con los valores ético-políticos y los hechos (Faralli, 2007, p. 13). Sin embargo, separados un poco de preocupaciones metafísicas, los positivistas han contribuido al esclarecimiento de la dimensión fáctica o institucional del derecho. Al respecto, se han ofrecido explicaciones sobre los elementos que componen la práctica jurídica en los términos más avanzados de teorías filosóficas sobre la mente, la acción y la ontología social (Bernal, 2008 , p. 26). Cada vez es más frecuente que las concepciones filosóficas desempeñen una función metateórica en el derecho. Así, muchas posiciones axiológicas, teórico-dogmáticas o empíricas sobre el derecho tienen correlato en teorías filosóficas sobre el método, el conocimiento, la argumentación, el razonamiento o la justicia.

El pluralismo teórico que acompaña los desarrollos filosóficos más recientes ha agudizado la posibilidad de análisis sobre la interpretación y argumentación jurídicas, la justificación racional, el razonamiento jurídico, la ontología jurídica, las fuentes del derecho, entre otros problemas. Varios discursos sobre un objeto compiten entre sí para subrayar diferentes aspectos de este. La tensión entre estos discursos genera una dialéctica entre objetividad y pluralismo que exige la integración de algunos presupuestos afines a la filosofía analítica y la tradición hermenéutica continental. 
La teoría analítica del derecho había usado la hermenéutica como metodología de la ciencia jurídica y del proceso de decisión; sin embargo, para algunos juristas, esto se basa en una autocomprensión falaz del fenómeno interpretado, pues es una ilusión establecer una separación real entre el derecho (códigos, precedentes) y su interpretación (Tontti, 2002, p. 120). La interpretación es vista como una actividad permanente dentro del derecho y no como un episodio teórico determinante para ciertos casos de aplicación de normas oscuras. En esta concepción, el análisis del concepto de derecho y sus elementos necesariamente se integra con la interpretación de una práctica social y no con el descubrimiento de las propiedades esenciales de la realidad mediante actos de intelección no observacional. En este marco, las conexiones entre análisis conceptual y hermenéutica exigen un reajuste teórico de ambas tendencias o, por los menos, enfatizar los aspectos metodológicos comunes.

Diego López (2012, p. 5) considera que la focalización en el derecho como lenguaje, en sus inicios, llevó a una actitud antihermenéutica basada, no en convicciones políticas, sino en tesis epistemológicas y lingüísticas. Por más plausible que parezca, esta tesis no propone un desencuentro genuino entre filosofía analítica e interpretación, pues el autor adopta una posición unilateral frente a las concepciones de la interpretación. Ya se indicó que en el movimiento analítico existen posiciones diferentes sobre el análisis conceptual, incluso se resaltó que una de ellas es incompatible con la filosofía hermenéutica. Si esto ocurre en el análisis filosófico, nada distinto puede esperarse de la tradición hermenéutica, pues sus desencuentros teóricos y metodológicos no son menos evidentes.

Para disolver el aparente desacuerdo identificado por López (2012) es necesario distinguir las diversas formas como ha sido comprendida la interpretación. Riccardo Guastini (2008, p. 16) diferencia entre teorías cognoscitivas y escépticas. Una teoría cognoscitiva considera que la interpretación es un acto de conocimiento cuyos enunciados tienen valor de verdad. Por el contrario, una teoría escéptica asume que la interpretación es un acto de voluntad cuyos enunciados carecen de valor de verdad. Si los enunciados lingüísticos son ambiguos e indeterminados, cada enunciado puede contener una multiplicidad de interpretaciones. Por tanto, el recurso a la discrecionalidad para adoptar una interpretación posible en el derecho, de ninguna manera supone una negación de la actividad interpretativa. En este orden de ideas, Kelsen (2005) y Hart (1998) no tienen una posición antihermenéutica; tal vez lo que reprocha López (2012) es que dichos autores se inscriben en una concepción escéptica en términos metaéticos, lo cual no presupone el carácter antihermenéutico de sus concepciones.

En la teoría jurídica contemporánea, el diálogo entre análisis filosófico e interpretación ha sido desarrollado por Ronald Dworkin, Joseph Raz, Michael Moore y Andrei Marmor, entre otros. Aunque no puede comprenderse el estado actual de la teoría del derecho sin el recurso de la filosofía analítica, tampoco puede sobrevalorarse su capacidad explicativa, pues el acentua- 
do énfasis puesto en el cúmulo de distinciones no ha permitido la solución o disolución de los problemas planteados. La capacidad explicativa del análisis conceptual se enriquece con su vinculación al pensamiento herménéutico. De ahí la fórmula "analítica sin hermenéutica es vacía, hermenéutica sin analítica es ciega", introducida por Kaufmann (1999, p. 87) e inspirada en la teoría kantiana sobre los conceptos.

\section{B. Críticas y limitaciones del análisis conceptual como modo de aproximación al derecho}

Las voces críticas que surgieron contra la filosofía analítica en la segunda mitad del siglo pasado (Rorty, 1998), en principio, no tuvieron mucho eco en la teoría del derecho, pues el método se aplicó con relativa persistencia en el estudio de las normas, el sistema normativo y el conocimiento jurídico. La transformación que sufrió el pensamiento jurídico a la luz del análisis conceptual es consecuencia de su manera particular de entender y abordar los problemas filosóficos. Sin embargo, este consenso relativo no se mantiene vigente, pues la multiplicación de estudios empíricos y estadísticos en el derecho ha opacado sus pretensiones de aplicación. En la actualidad, el análisis conceptual es objeto de algunas críticas que discuten su plausibilidad y relevancia como método para abordar problemas filosóficos y jurídicos. Estos cuestio- namientos no solo sugieren una discusión metodológica sino que generan dudas sustanciales de cara a los enfoques filosóficos adoptados.

El análisis filosófico ha sido acusado de trivial y carente de interés, pues no proporciona conocimiento sino que se limita a formulación de proposiciones analíticas derivadas de definiciones formales. A esta crítica le subyace la idea que el análisis de un concepto consiste en desplegar sus elementos constituyentes para eliminar malentendidos o confusiones. En este ejercicio de descomposición de los conceptos en sus partes más simples, no se obtiene más resultado que la clarificación de proposiciones con sentido. En esta perspectiva, el análisis como terapia se convierte en una actividad negativa que no aumenta el conocimiento (Strawson, 1997, p. 63). Sin embargo, no es esta concepción clásica del análisis conceptual la que se aplica en la teoría del derecho, pues con ella no se busca la clarificación de los significados de las palabras sino la explicación de una institución social imbricada en la autocomprensión de nuestra sociedad (Raz, 2007, p. 65). Los conceptos tienen conexión con prácticas complejas que requieren de un conocimiento que mejore la comprensión del objeto.

La trivialidad y la falta de interés del método analítico también están asociadas a las posiciones metaéticas no cognitivistas ${ }^{16}$ compartidas por algunos filósofos analíticos, quienes pretenden ofrecer una teoría descriptiva de

16. Ronald Dworkin (2007, p. 45) hace una valoración crítica del escepticismo ético que pretende evitar con la dimensión argumentativa del discurso jurídico asociada a un ideal de corrección. A su vez, John Finnis (1980) sostiene que es posible determinar por vía cognoscitiva la moralidad o inmoralidad de determinadas prácticas. 
una práctica social tan compleja como el derecho (Bix, 2006, p. 18). ${ }^{17}$ Este argumento debe acusarse de parcialidad y de excesiva generalidad, pues esta forma de análisis conceptual no tiene compromisos esencialistas y objetivantes. Los conceptos son diversos y cambian en el transcurso del tiempo, pero el objeto del análisis conceptual es nuestra comprensión del concepto de derecho (Raz, 2007, p. 65). Además, la imposibilidad del conocimiento objetivo de los valores tampoco supone un rechazo al análisis conceptual del derecho, por lo menos puede ser consecuente con la versión esencialista de tal actividad como es asumida por Alexy cuando pretende la identificación de un concepto correcto de derecho (Gaido, 2011, p. 76). El conocimiento de los valores no es un asunto que pueda considerarse resuelto en la teoría constitucional del derecho pese a la frecuencia de uso de las técnicas de ponderación. El resultado de esta técnica es imprevisible y su aplicación no deja de ser una decisión valorativa o un cálculo costo-beneficio como lo considera Habermas (1998, p. 333).

Otra forma de realizar el análisis conceptual consiste en sustituir los términos del lenguaje natural por variables, constantes y predicados lógicos. Los conceptos equívocos del lenguaje ordinario se reemplazan por términos unívocos de notación lógica para disolver las confusiones
(Russell, 2003; Von Wright, 1979; Alchourrón y Bulygin, 2002). Esta orientación formalizante también ha sido criticada porque deja de lado al lenguaje ordinario, a pesar de lo mucho que ha contribuido a la comprensión de la estructura del derecho y de haber sido tomada como referente para proponer que el análisis conceptual debe ser reemplazado por el análisis empírico. Esta posición conocida como naturalismo supone que a los campos de investigación en el derecho les son aplicables las metodologías de las ciencias naturales. En este contexto, como la teoría del derecho no ha abandonado el análisis conceptual por un análisis empírico, se encuentra rezagada frente a los desarrollos de la filosofía analítica (Leiter, 2007). Este argumento es replicado por Bix (2006, p. 43), quien considera que la observación empírica no soluciona las controversias relacionadas con el uso de los conceptos que determinan una práctica.

Pese a las críticas sobre el carácter tautológico de la analiticidad y la tendencia idealista de la formalización, está claro que el análisis filosófico se ocupa de dilucidaciones lingüísticas. Distinguir, sin duda puede ayudar a clarificar los problemas; sin embargo, el exceso de distinciones conceptuales como recurso metodológico no siempre envuelve una comprensión más clara o completa del problema que se aborda. ${ }^{18}$ Hacer distinciones donde no

17. Brian Bix (2006, p. 20) recoge los argumentos de John Finnis contra las teorías descriptivas, quien señala que corren el riesgo de no ser más que lexicografía e historia local. Bix se refiere a Natural Law and Natural Rights, de Finnis, publicada en 1980, en Oxford, por Clarendon Press.

18. Llama la atención que un analítico como Guastini (1999) haya reducido su actividad académica a la formulación de tipologías conceptuales. Algunos resultados se traducen en estériles clasificaciones que no aportan una explicación. No siempre es suficiente distinguir para clarificar un problema. 
existen contradice el propósito central del método analítico, pues multiplica los problemas que trata de resolver o reconduce a pseudoproblemas que terminan en extensas clasificaciones de todo lo hecho y por hacer en el derecho. ${ }^{19}$ Por tanto, estas distinciones aumentan a priori los discursos que, desde una perspectiva conceptual o empírica, se entrecruzan. Descomponer conceptos o hacer definiciones o distinciones no es el único modo de realizar el análisis. El conocimiento de los conceptos puede aumentarse si se establecen conexiones entre sí.

Las conexiones entre conceptos implican que el análisis conceptual no se agota en mirar el lenguaje o las proposiciones de manera aislada. Explicar un concepto significa dar cuenta de su posesión y comprensión (Strawson, 1997, p. 50). Esto supone que ciertos conceptos no son completamente convencionales, pues aluden a prácticas sociales. Así, los conceptos parecen ser empleados de manera diversa en contextos discursivos diferentes. En la tradición analítica de la filosofía se ha considerado que la actividad filosófica es sustancialmente análisis conceptual de la estructura del derecho y sus componentes (Bulygin, 2009, p. 87). Sin embargo, el análisis conceptual debe ser integrado a otros elementos que dan cuenta de la práctica jurídica, lo cual recrea vínculos con orientaciones filosóficas hermenéuticas y postanalíticas.

Las clarificaciones conceptuales son necesarias para una adecuada formulación de acuerdos teóricos o prácticos; de lo contrario, los consensos no serían genuinos y los desacuerdos no más que ilusiones. Conceptos formulados de manera precisa en tareas de explicación son indispensables para la existencia misma de prácticas en el derecho. Esta actividad, como presupuesto metodológico, es fundamental, pues los participantes requieren unos criterios de uso compartidos para la aplicación de conceptos jurídicos. Puede verse a la filosofía como una metajurisprudencia descriptiva o prescriptiva de las operaciones llevadas a cabo por los juristas, que puede controlar la actividad cognoscitiva del derecho. Aunque el carácter descriptivo o prescriptivo del método jurídico ha sido contrapuesto, no se trata de ideas incompatibles metodológicamente. En la actualidad es frecuente encontrar teóricos del derecho que atribuyen ambas funciones a la filosofía analítica del derecho por cuanto se ocupa del análisis de la dogmática y de la teoría del derecho (Ferrajoli, 2000, pp. 52-53). Pocos son los filósofos analíticos que consideran a la teoría del derecho como una actividad de carácter descriptivo, pues la filosofía es una actividad normativa (Nino, 1994).

19. La diferencia entre la "filosofía del derecho de los juristas" y la "filosofía del derecho de los filósofos" no representa una distinción clara entre estas ni nos dice algo de las relaciones entre filosofía y derecho. Asumir como criterio de distinción conceptual a los sujetos para formar un concepto de filosofía jurídica no nos dice en qué consiste la filosofía ni cuáles son sus rasgos fundamentales. Tampoco es claro que el método analítico o esencialista sea distinto si lo usa un jurista o un filósofo. 


\section{EL ANÁLISIS CONCEPTUAL Y LA POSICIÓN DE LOS PARTICIPANTES. EL DISCURSO JURÍDICO COMO OBJETO DE ANÁLISIS FILOSÓFICO}

Aunque el análisis conceptual ha sido frecuente entre los iusfilósofos, no puede pensarse que sea la única forma disponible para dar cuenta del fenómeno jurídico en la actualidad. ${ }^{20}$ Esto no implica que nuevas aproximaciones al derecho dejen de lado el análisis conceptual, sino que este aparece como un presupuesto metodológico dado que da orientaciones sobre el uso y la estructura del lenguaje jurídico, de un lado; y sobre las prácticas e instituciones sociales, de otro. La creciente complejidad de los sistemas jurídicos ha provocado no solo transformaciones en la práctica del derecho, sino que ha enriquecido el papel de la filosofía, la cual se ha ocupado tanto de conceptos generales como de abordar problemas puntuales referidos al conocimiento de los hechos (González, 2000), pasando por la argumentación jurídica (Alexy, 1989; Atienza, 2006) y los valores políticos (Dworkin, 1986; Alexy, 1993).

Teoría de la justicia, ciencia jurídica, normas y ordenamiento jurídico constituyen problemas clásicos tratados por la filosofía del derecho; sin embargo, han sido tratados de manera global. Este nivel de generalidad y abstracción es cada vez menos frecuente, pues el debate filosófico jurídico posthartiano ha sido más especializado $^{21}$ y fragmentado (Faralli, 2007, p. 12). Incluso, los filósofos han comenzado a ocuparse de problemas específicos en las distintas áreas del derecho y sus respectivas dogmáticas. ${ }^{22}$ La especialización del análisis filosófico exige un diálogo más fluido con otras disciplinas o ciencias sociales, con el fin de proporcionar una explicación más comprensiva de las prácticas jurídicas. En esta dirección, la filosofía del derecho ha tenido apertura a valores sin ser excesivamente metafísica, pues ha desarrollado procedimientos para llegar a razonamientos ponderados (Alexy, 2009, p. 68). Así las cosas, el principio de proporcionalidad es un desarrollo de la teoría de la argumentación para orientar la aplicación de normas con estructura de principios (Lopera, 2004, p. 212). La filosofía del derecho también se ha ocupado de los hechos en el derecho sin caer en la ilusión objetivista del empirismo ni en los espejismos conceptuales del idealismo; por el contrario, ha adoptado una postura moderada en términos epistemológicos (González, 2000). En este or-

20. Norberto Bobbio (2012, p. XI) ha señalado que el análisis estructural del derecho puede ser complementado con un análisis funcional, el cual es consecuencia de estudios renovados de la sociología del derecho.

21. Cabe resaltar la participación de los filósofos del derecho en polémicos debates sobre eutanasia, aborto y derechos de parejas del mismo sexo, entre otros.

22. Este argumento deriva de la propuesta del profesor Roberth Uribe (2008) consistente en crear un programa para el curso de Filosofía del Derecho, de la Universidad de Antioquia, que se ocupe de abordar problemas específicos que poseen un carácter filosófico, a los cuales considera como desafíos de la razón práctica contemporánea a la filosofía del derecho. En consecuencia, propone estudiar asuntos filosófico-jurídicos desde el derecho constitucional, internacional, laboral, privado, procesal, entre otros. A este mismo propósito responde la línea de investigación en filosofía del derecho constitucional, del grupo de investigación Saber, Poder y Derecho de la misma universidad, del cual es coordinador. 
den de ideas, el análisis del derecho exige posiciones consecuentes con el pluralismo teórico y metodológico a fin de comprender las prácticas que se producen en todos sus niveles.

El quehacer jurídico discurre como una serie de hechos sociales susceptibles de consideraciones ontológicas, epistemológicas y axiológicas. Por tanto, no es necesario acudir a criterios extralingüísticos para comprender 0 explicar las convicciones teóricas, metodológicas o normativas, tampoco conviene recurrir a especulaciones metafísicas para justificar cierto tipo de prácticas jurídicas. La aplicación de una norma jurídica no es una cuestión que pueda ser contestada exclusivamente con un análisis de la estructura del derecho y sus componentes. Una articulación de la tradición conceptual en el análisis del derecho con otras perspectivas de análisis puede permitir, entre otros aspectos, realizar una aproximación a otros elementos del fenómeno jurídico. Así las cosas, el análisis filosófico debe acercarse a las teorías hermenéuticas sin darle primacía a elucidaciones lógicas. La reconstrucción de los conceptos debe hacerse en función de los discursos jurídicos.

El derecho es una realidad construida como todos los hechos o instituciones sociales (Searle, 1995, p. 21), y consiste en una práctica social que cobra sentido cuando los sujetos derivan o introducen razones para actuar de cierta manera. Las convenciones en sí mismas no se pueden entender sin tomar en cuenta el punto de vista interno de quienes participan en ellas (Nino, 1994, p. 30). Así, el derecho es el resultado de acciones y estados mentales de los participantes en el sistema jurídico. Este es el escenario propicio para explicar las relaciones que existen entre los elementos que conforman el derecho, entre ellos, sus prácticas discursivas. Una práctica social no se agota en comportamientos externos, también es necesario tener en cuenta creencias y actitudes de los participantes (Nino, 1994, p. 24). La existencia del derecho no es independiente de los comportamientos y posiciones de las autoridades y destinatarios.

En términos analíticos, en la práctica jurídica es posible distinguir actividades de creación, interpretación, aplicación y obediencia del derecho. En esta pluralidad de actividades los individuos participan con discursos. En consecuencia, la práctica puede ser entendida como una acción colectiva intencional desarrollada por los participantes (Shapiro, 2014, p. 253). El derecho es un producto social constituido en el seno de la comunicación lingüística, y regulado por estipulaciones o acuerdos semánticos. El derecho es lo que se dice de él (García Amado, 1992, p. 55). Lo que se dice del derecho supone el reconocimiento de discursos que lo constituyen como objeto y determinan el modo de entenderlo y practicarlo como resultado de significados históricamente determinados. La concepción del derecho como lenguaje relativiza notablemente su dimensión hasta el punto que las normas no tienen existencia previa e independiente a su interpretación.

El derecho y sus instituciones no poseen justificaciones intemporales en la justicia o la libertad. De cierta forma, el derecho consiste en una 
práctica creadora de significados, ordenadora de la vida social y generadora de discursos. La discursividad del derecho no está referida a la existencia de procedimientos para llegar a consensos, sino que alude a estándares argumentativos que facilitan la realización de pretensiones de los sujetos. La percepción de que hay diversos discursos relacionados con el derecho, con funciones y puntos de vista diferentes, hace pensar que en ellos se emplean conceptos de derecho distintos aunque estén relacionadas entre sí (Nino, 1994, p. 32). En consecuencia, el análisis conceptual de los discursos debe recaer sobre estas prácticas lingüísticas de los individuos a fin de comprenderlas.

Al participar en el discurso jurídico se recrea permanentemente un objeto que no existe más allá de las convenciones (Bayón, 2000, p. 116), pues al margen de los comportamientos de autoridades y usuarios, no existen estados de cosas que hagan verdaderas o falsas las proposiciones jurídicas o las interpretaciones del derecho. Los discursos articulados por los participantes inciden en la práctica jurídica. El análisis filosófico del discurso es una manera de explicar la positividad del derecho, pues su existencia está vinculada al acaecimiento de ciertos actos llevados a cabo por autoridades y destinatarios de las normas. Una teoría, en este marco, da cuenta de la relación que existe entre normas jurídicas y hechos sociales a través de prácticas discursivas.
El derecho, como una acción colectiva intencional desarrollada por los participantes, comporta escenarios para la realización de pretensiones. Las pretensiones toman en cuenta valoraciones que hacen los participantes en la práctica jurídica. Este concepto de pretensión no presupone la dimensión ideal sugerida por Alexy $(2009$, p. 68) para el concepto de derecho. Por el contrario, las pretensiones hacen parte de la dimensión fáctica o institucional del derecho y se concretan en la articulación de intenciones e intereses formulados al sistema jurídico por los participantes. La pretensión de corrección no corresponde al sistema como tal sino a sus participantes, es decir, legislador, jueces, juristas, abogados, entre otros (Alexy, 2008, p. 63). En este contexto la pretensión discursiva y la pretensión de corrección guardan cierta relación; sin embargo, aquella está desprovista de la dimensión ideal que la asocia con una pretensión de justicia o una pretensión moral. Los participantes pueden considerar que cierta pretensión es exigible en un sistema jurídico dado, pero de esta circunstancia no se sigue que sea la más correcta.

El concepto alexiano de pretensión hunde sus raíces en la teoría de los actos de habla de Austin (1982). En tal virtud, el acto de prescribir supone una creencia en su corrección. Lo contrario produciría una contradicción pragmática que, en sentido amplio, es una falla conceptual para Alexy (2004, p. 43). ${ }^{23}$ La afirmación "esto es derecho, pero es injusto" es una contradic-

23. Paula Gaido (2011, p. 24) señala que el punto de controversia en el debate Alexy-Bulygin está en que sostienen perspectivas diferentes de lo que es una "relación conceptual", pues la nota definitoria de lo conceptual para Bulygin es una referencia arbitraria y convencional a hechos, mientras que Alexy acude a una perspectiva esencialista. 
ción performativa, pues existe una conexión necesaria entre derecho y pretensión de corrección como justicia (Alexy, 2008, p. 65). Al margen del alcance definitorio o clasificatorio que Alexy le otorga a la pretensión de corrección, el derecho como discurso supone que los participantes buscan la realización de ciertos propósitos con el apoyo de argumentos o razones para actuar. La pretensión está dirigida a concretar las exigencias de un sistema jurídico sin parámetros externos a la práctica misma.

La introducción de razones o la consolidación de discursos implican una reconfiguración semántica de los conceptos y una interpretación determinada de los textos normativos. Los sujetos jurídicos tienen la creencia de que en la interpretación del sistema jurídico reposa la justificación necesaria y suficiente de lo que hacen. Esta posición sobre el derecho, propia de una concepción postpositivista pero no incompatible con el iuspositivismo, recalca su carácter indeterminado (Calsamiglia, 1998, p. 209) y sustenta que el razonamiento jurídico es parte del razonamiento práctico general (Alexy, 1989, p. 205). La indeterminación del derecho es funcional a la realización de las pretensiones de los participantes en el sistema jurídico. En concordancia, el análisis conceptual del derecho requiere algo más que un análisis de sus normas y de la estructura del ordenamiento, es necesaria la caracterización de las formas argumentativas que justifican las prácticas jurídicas existentes. El trasfondo es el análisis de los criterios de corrección que están presentes en la elección de las premisas que definen el derecho según la pretensión de los participantes.
Los enunciados jurídicos no son leídos en sí mismos, como entidades platónicas, sino desde discursos que articulan pretensiones de corrección jurídica, económica y política. A las disposiciones de derecho positivo se acude a partir de consideraciones de conveniencia para resolver problemas. El uso de ciertos conceptos en el derecho supone que no siempre se recurre a los mismos significados cuando se asocian a diversas prácticas discursivas. El concepto de discurso que aquí se construye para explicar el derecho consiste en una práctica argumentativa, es decir, en una serie de razones utilizadas para configurar un estado de cosas.

El discurso jurídico se diferencia de una teoría de la argumentación en que no tiene como objeto la estipulación de reglas para la sustentación de posiciones jurídicas. Tampoco es una metodología jurídica que pretenda resolver el problema de la fundamentación de las decisiones jurídicas con reglas o procedimientos a partir de los cánones de interpretación (Alexy, 1989, p. 24). De cierta forma, el discurso supone determinada concepción de la teoría de la argumentación y se extiende hasta la filosofía moral y política, que posee una finalidad práctica. Los discursos cobran sentido en atención a las distintas clases de actividad. La pluralidad de discursos y actores hace que los juristas no entiendan lo mismo ni hagan las mismas cosas con los conceptos jurídicos.

La elección de los discursos que le dan sentido a los conceptos jurídicos depende de factores sociales, políticos, históricos, morales e ideológicos. Los discursos tienen una dimensión 
práctica que depende de preferencias individuales y subjetivas. La función de los discursos es asegurar cierto orden de conductas y permitir que las soluciones alcanzadas, de conformidad con ese orden, sean legítimas. Los discursos consisten en la selección de principios de justicia y reglas de prioridad que no siempre son imparciales en la justicia constitucional.

Este hecho evidencia que el derecho tiene una dimensión política, es un fenómeno que tiene relaciones intrínsecas con la práctica política (Nino, 1994, p. 11). Las prácticas discursivas no solo buscan la reconstrucción del derecho positivo sino la obtención de legitimidad. Para ganar legitimidad ingresan en el ámbito de la deliberación pública. En este orden de ideas, el derecho como una práctica discursiva supone la instrumentalización de los conceptos jurídicos para incidir en la manera como debe ordenarse la sociedad. A los discursos subyacen desacuerdos irreconciliables, que se ponen en juego como formas de hablar que se dirigen a convencer a distintas clases de auditorios. La filosofía busca comprender la gramática de los discursos que subyacen a la práctica del derecho.

Esta posición permite llegar a una concepción del derecho como conformado por un conjunto de discursos que los participantes producen o derivan de los enunciados normativos. Bien sea desde una perspectiva institucionalista del derecho o desde cualquier otra, la posición de los participantes debe situarse en el marco de una teoría de la acción. Una institución como el derecho consiste en prácticas que se desa- rrollan a la luz de normas, fines y preferencias. El discurso pretende ofrecer una función unificadora de las prácticas jurídicas, similar a la desarrollada en el pasado por el código y la ley. Para Robert Alexy (1989, p. 43), una argumentación es correcta si ha sido producida con sujeción a reglas racionalmente justificadas. Por el contrario, el discurso tiene una justificación final no formal, es decir, cuenta si es idóneo para el logro de ciertos fines o si es representativo de intereses derivados de un cálculo costobeneficio. Con reglas procedimentales pueden juzgarse como correctos discursos radicalmente opuestos.

\section{DISCURSOS DOGMÁTICOS Y JUSTIFICACIÓN FÁCTICO-NORMATIVA DE LOS DERECHOS SOCIALES}

Las discrepancias teóricas y epistemológicas en torno a la dogmática en general, también son aplicables a la dogmática constitucional. Este argumento es aceptable desde el presupuesto metodológico que reconoce la división del conocimiento dogmático en disciplinas y subdisciplinas que estudian el derecho a partir de ramas específicas (Vernengo, 1988, p. 30). Los constitucionalistas, por ejemplo, disponen de un aparato conceptual para identificar su disciplina, la cual puede ser reconstruida como un conjunto sistemático de teorías que involucra conceptos propios. Sin embargo, varias circunstancias, señaladas posteriormente, han generado desacuerdos sustantivos sobre los aspectos relevantes que hacen parte de tales conceptos y sobre las mejores teorías para en- 
tenderlos. Cómo comprender la actividad dogmática es un problema que exige identificar las contradicciones metodológicas en algunas concepciones del saber jurídico.

En principio, la dogmática jurídica tiene tres dimensiones: analítica, empírica y normativa. ${ }^{24}$ La dimensión analítica hace una consideración sistemático-conceptual del derecho válido; estudia conceptos básicos, hace construcciones jurídicas e investiga la estructura del sistema jurídico. La dimensión empírica comporta el conocimiento del derecho positivo válido y la utilización de premisas empíricas en la argumentación jurídica; por tanto, no se trata solo del derecho legislado sino de la decisión y pronóstico de la praxis judicial. La dimensión normativa orienta y critica la praxis jurídica, ${ }^{25}$ en lo cual es fundamental la decisión correcta sobre el derecho válido (Alexy, 1993, pp. 29-31). El tercer elemento señalado por Alexy como dimensión de la dogmática jurídica ha sido decisivo en el debate contemporáneo entre positivistas y no positivistas y, de cierta manera, justifica una concepción discursiva del derecho.

Las razones para sostener una concepción normativa de la dogmática jurídica son de diverso tipo. Entre otras, se destacan razones de orden axiológico con pretensiones de preservación del orden vigente, y razones críticas y progresistas que ven en la dogmática la dimensión racional y política del derecho. El carác- ter normativo de la dogmática abre paso a la formulación de argumentos dogmáticos, políticos, morales o sociológicos que implican justificaciones racionales sobre el por qué deben ser utilizados en el sistema jurídico. La concepción normativa de la ciencia jurídica se enlaza directamente con los discursos que involucran argumentaciones jurídicas racionales.

El objeto de estudio de la dogmática constitucional es el derecho positivo vigente que se ocupa de la constitución del Estado y los derechos reconocidos a los individuos. Las fuentes de su estudio consisten principalmente en normas, constituciones y jurisprudencia, las cuales están precedidas y acompañadas de discursos que permiten comprender las formas de existencia y justificación jurídica de los derechos. Señalar que la Constitución es el objeto de los estudios dogmáticos, en principio parece problemático, pues esta, entendida como derecho objetivo, aparece no solo como instrumento para la realización de algunos fines, sino que en sí misma posee un valor ético reconocido por los constitucionalistas. En este contexto, el derecho pretende la conformación no solo de un orden sino de un orden justo (Alexy, 2009, p. 69). Esta pretensión lleva a la pregunta por la fundamentabilidad de los enunciados valorativos que socava sus cimientos como saber en sentido estricto. Sin embargo, en cuanto práctica discursiva, el concepto de Constitución compartido por sus juristas

24. Este concepto es contrario a la concepción kelseniana de la ciencia jurídica. Kelsen (2002, p. 85) trató de refundir la ciencia jurídica a la luz de postulados neopositivistas y con posiciones escépticas en el ámbito de la razón práctica.

25. Con importantes diferencias entre sí, esta posición es compartida por Ferrajoli (1995), Zagrebelsky (2007), Nino (2003), entre otros. 
evidencia las consecuencias morales, políticas y sociales que subyacen a los discursos constitucionalistas.

Si a nivel general existen dificultades en la construcción del objeto, a nivel específico los problemas no son menores. La consideración de que la Constitución está compuesta por disposiciones jurídicas que definen el contenido y alcance de los derechos, implica caracterizar tales elementos desde una perspectiva conceptual. Sin embargo, los criterios de uso siguen siendo problemáticos. Las disposiciones constitucionales no contienen mandatos definitivos, pues son consideradas normas con estructura de principio cuyo contenido depende de la introducción de reglas de precedencia (Alexy, 1993, p. 103). Los altos niveles de indeterminación de las normas constitucionales han permitido considerar, en la teoría del derecho constitucional, que además de las normas estatuidas directamente por el texto supremo existen otras normas adscritas, las cuales se obtienen argumentativamente (Alexy, 1993, p. 70). Por esta razón, lo que dice la Constitución adquiere sentido a la luz de la interpretación judicial. Los juristas dogmáticos son cercanos a las autoridades jurisdiccionales, quienes tienen en común el hecho de ser no solo intérpretes sino admiradores de la Constitución y su jurisprudencia.

La dogmática constitucional se compone de discursos que tratan de establecer qué es una Constitución y cuál es la posición y el tratamiento que deben recibir sus normas. Estos discursos no son indiferentes a la función judicial y al significado que tiene la jurisprudencia, la cual está dominada por un complejo sistema de precedentes. La metodología del precedente, sistematizada por López (2007, p. 139), ha pretendido controlar la producción de los discursos válidos y ha llevado al discurso académico a un ejercicio de repetición e identificación de pronunciamientos del juez constitucional. Sin embargo, el panorama no es de coherencia interpretativa, pues los discursos asociados representan estándares argumentativos en controversia por el control interpretativo de lo jurídico. En este contexto, los constitucionalistas promueven la existencia de un derecho dúctil y una dogmática fluida (Zagrebelsky, 2007, pp. 14-17). Así, la dogmática constitucional estructura sus presupuestos metodológicos y epistemológicos que coadyuvan a la comprensión de la Constitución.

Para algunos constitucionalistas, la Constitución funciona como lo obvio, lo natural, lo transparente, lo cual parece ocultar que el discurso constitucional obedece a distintas clases de intereses. Por tanto, surge la necesidad de indagar por las condiciones de posibilidad externas del discurso (Foucault, 1992, p. 33), es decir, preguntar de dónde surgen, a qué intereses responden y cuáles son sus límites. Es así como la filosofía proporciona un enfoque para el análisis del uso discursivo del derecho constitucional. La racionalidad del derecho constitucional se orienta hacia la justificación interna de reglas y valores que pueden ser identificados en la legislación, la jurisprudencia y la dogmática jurídica. No es otra la actitud que puede asumirse en el marco de una Constitución cargada de contenido material, y de la tendencia comprometida de sus juristas. 
El filósofo realiza un análisis conceptual y metaconceptual del derecho y sus discursos, es decir, describe la estructura epistemológica que subyace a las creencias, convicciones 0 presupuestos de los participantes en el sistema jurídico. El análisis del filósofo también es metanormativo, es decir, intenta comprender la estructura racional de la crítica realizada por los juristas sobre el derecho. Atiende no solo a la coherencia pragmática que se espera del legislador racional sino a la congruencia valorativa de los precedentes y la interpretación de los principios. La filosofía del derecho se ocupa de examinar las creencias conceptuales y valorativas respecto del derecho, pues una sus funciones es examinar críticamente los supuestos y creencias (Popper, 1974, p. 23). De cierta manera, su cometido es reconstruir los presupuestos que posibilitan la conceptualización o normatividad del derecho vigente.

El análisis filosófico busca incidir en el significado práctico de los conceptos para desempeñar una función racionalizadora de las actividades de creación, interpretación y aplicación. Nótese que los problemas de justificación no constituyen un campo exclusivo de la filosofía del derecho y la dogmática. Un ejercicio analítico sobre los derechos sociales, desde una perspectiva metodológica, se distancia de reduccionismos epistemológicos o adopta una posición escéptica frente a la sustancialización de los conceptos (García Amado, 1992, p.
57). Así, a un objeto jurídicamente complejo le corresponde una perspectiva teórica pluralista para dar cuenta de su estructura normativa y de sus aplicaciones prácticas. El carácter discursivo del derecho pone de presente la dificultad epistemológica de sustancializar los conceptos jurídicos como, de cierta manera, ocurre con especulaciones en abstracto sobre Ios derechos sociales. En un ejercicio filosófico sobre el derecho, los diversos modos de interpretación y aplicación de las normas y los usos de los conceptos jurídicos se convierten en objeto de análisis crítico.

En principio, el concepto discurso no parece una categoría adecuada para explicar la jurisprudencia de los derechos sociales. Sin embargo, pese a los esfuerzos que se hagan para proporcionarle a los derechos una estructura normativa, el problema estará ligado a las pretensiones discursivas de los participantes en el sistema jurídico. En el marco de la autonomía e independencia judicial se encontrarán decisiones a favor y en contra. Es posible reconocer que los derechos fundamentales tienen un alto nivel de importancia (Arango, 2005, p. 31); sin embargo, lo principal para un economista será la sostenibilidad del sistema y para el moralista la defensa de la dignidad humana. Por más fuerza normativa que se le dé a la Constitución, siempre estará determinada por lecturas discursivas que coadyuvan a la realización de determinadas pretensiones. ${ }^{26}$

26. Esta tesis tiene mayor fuerza argumentativa si se tiene en cuenta que el control constitucional a la economía es un control de razonabilidad (Uprimny y Rodríguez, 2006, p. 30). Se trata de una forma de control leve y flexible que solo examina objetivos y medios en términos generales. 
La versión estándar del neoconstitucionalismo colombiano ha estado comprometida con la construcción de discursos que buscan la expansión de las promesas políticas consagradas en la Carta de derechos de 1991. En consecuencia, se ha tratado de fundamentar la normatividad de los derechos sociales para fortalecer sus condiciones jurídicas de exigibilidad (Arango, 2005, p. 98), se ha justificado la función activista o protectora del juez constitucional (Uprimny, Rodríguez y García, 2006, p. 44) y se ha consolidado una defensa política y jurídica de la Constitución (Bernal, 2005, p. 130). La posición crítica al neoconstitucionalismo, que proviene de sectores económicos, ha consolidado discursos que hacen ver los derechos sociales como derechos disminuidos que tienen poca fuerza normativa al momento de su aplicación o que comportan nefastas consecuencias para el funcionamiento de la economía (Clavijo, 2001, p. 38).

La primera tendencia acude al arsenal de los argumentos morales y políticos en defensa de los derechos; la segunda se apoya en principios estadísticos y fundamentaciones de naturaleza científica con expresión en variables económicas. Si bien en ambas tendencias existe un creciente interés en la producción de discursos, no se visualiza un análisis sobre el uso que tienen dichas prácticas discursivas en la justiciabilidad de los derechos sociales. En este contexto, existen tensiones, regularidades y discontinuidades que subyacen a prácticas discursivas dominantes en el constitucionalismo de los derechos. Intereses contradictorios e incompatibles encuentran en el texto consti- tucional el presupuesto normativo para la protección de aspiraciones morales o la defensa de modelos económicos.

Para el discurso de los derechos, un acuerdo que tenga naturaleza constitucional supone una mayor fuerza democrática, política y jurídica como resultado del balanceo de principios en conflicto. Este hecho despierta interés para el análisis de las prácticas argumentativas que subyacen a la formación de los discursos del constitucionalismo de los derechos, pues la Constitución como conjunto de enunciados refuerza el poder de las prácticas discursivas que determinan su contenido y alcance. En otras palabras, la lucha es uno de los usos que puede tener el discurso de los derechos, pues diversas clases de poder identifican formas de protección de lo jurídico.

La oposición entre lo constitucional y lo inconstitucional determina la naturaleza de los derechos, define el alcance de la razón práctica y representa modalidades de dominación. El control sobre esta clase de discurso ha sido criticado por su carácter elitista, pues los tribunales constitucionales carecen de legitimación democrática (Waldron, 2005, p. 62). En este caso, no se trata de un control democrático sino técnico, en el cual el alcance de un acuerdo político adquiere sentido en la interpretación de un grupo de expertos. Así la interpretación autorizada de la Constitución se convierte en la reiteración de agrupaciones teóricas y en el origen de significados coyunturales y transitorios. De esta manera, la forma de visibilizar problemas y analizar el derecho ha sido im- 
puesta con el argumento de autoridad y sustentada en una retórica moral, política y económica. El discurso judicial ha sido dominante y ha colonizado la posibilidad de analizar formas de exclusión, delimitación y apropiación de los discursos de los derechos. Entre otros, los discursos legislativo y jurisprudencial han centrado su atención en las aspiraciones políticas y en las limitaciones económicas que suponen la garantía de los derechos sociales.

\section{CONCLUSIONES}

El análisis de las prácticas discursivas en el derecho lleva a concluir que la existencia de desacuerdos no siempre permite adecuar el derecho a pautas de racionalidad. Los desacuerdos no son irrelevantes al momento de construir o analizar conceptos que describen las prácticas de los participantes en el sistema jurídico. Los participantes no se refieren a lo mismo cuando hablan de derecho, por tanto, no tienen desacuerdos sobre el mismo objeto aunque usen los mismos conceptos. El contenido de los desacuerdos que se presentan en el derecho implica la ausencia de criterios para determinar la corrección de las posiciones adoptadas.

La determinación de lo que exige el derecho pasa por la formación de discursos para la satisfacción de pretensiones en un sistema jurídico determinado. La reconstrucción de los conceptos en disputa permite la comprensión de prácticas jurídicas. Los participantes suelen defender las mismas instituciones o conceptos pero sus posiciones teóricas y metodológicas son irreconciliables. El análisis del discurso jurídico implica hacer explícitos los presupuestos básicos de la actividad filosófica, por la multiplicidad de tendencias que integran el discurso filosófico. Un enfoque analítico posibilita la explicación de las estructuras conceptuales usadas para dar cuenta del mundo e identificar las relaciones que subyacen a las prácticas jurídicas. El análisis conceptual libera a la teoría del derecho de la inconsciencia metafísica al explicar fenómenos o prácticas sociales.

Las ideas filosóficas desempeñan una función metateórica en el derecho. Varios discursos compiten para resaltar aspectos diferentes sobre el mismo objeto. La caracterización de los discursos que implican tensiones sustantivas, exige la integración de algunos presupuestos de la filosofía analítica con la tradición hermenéutica continental. Las clarificaciones conceptuales son necesarias para la formulación e interpretación de desacuerdos teóricos y prácticos. Los participantes requieren criterios de uso compartidos para la comprensión y aplicación de conceptos jurídicos. En este contexto, el derecho consiste en una realidad social construida, la cual es producto de acciones y estados mentales de los participantes.

Los usos discursivos del derecho se explican porque el derecho es construido en el seno de la comunicación lingüística. El análisis de tales discursos es una manera de explicar la positividad del derecho. El derecho como una acción colectiva comporta escenarios para la realización de pretensiones, las cuales están dirigidas a concretar exigencias del sistema jurídico. La 
filosofía analiza los criterios de corrección presentes en la elección de premisas que definen el derecho. El derecho es interpretado desde pretensiones de corrección jurídica, económica y política. Por tanto, los discursos consisten en la selección de principios de justicia y reglas de prioridad que no siempre son imparciales en la justicia constitucional. La filosofía busca comprender la gramática de los discursos que subyacen a la práctica del derecho.

\section{Referencias}

1. Alchourrón, C. E. y Bulygin, E. (2002). Introducción a la metodología de las ciencias jurídicas y sociales. Buenos Aires: Astrea.

2. Alexy, R. (1989). Teoría de la argumentación jurídica. La teoría del discurso racional como teoría de la fundamentación jurídica (M. Atienza e I. Espejo, Trads.). Madrid: Centro de Estudios Constitucionales.

3. Alexy, R. (1993). Teoría de los derechos fundamentales (E. Garzón Valdés, Trad.). Madrid: Centro de Estudios Constitucionales.

4. Alexy, R. (2004). El concepto y la validez del derecho. Barcelona: Gedisa.

5. Alexy, R. (2007). Acerca de dos yuxtaposiciones: concepto y naturaleza, derecho y filosofía. Algunos comentarios sobre “¿Puede haber una teoría del derecho?" de
Joseph Raz. En J. Raz, R. Alexy y E. Bulygin, Una discusión sobre la teoría del derecho (págs. 87-97). Madrid: Marcial Pons.

6. Alexy, R. (2008). El concepto y la naturaleza del derecho (C. Bernal Pulido, Trad.). Madrid: Marcial Pons.

7. Alexy, R. (2009). Los principales elementos de mi filosofía del derecho. Doxa: Cuadernos de Filosofía del Derecho, (32), 67-84.

8. Alexy, R. y Bulygin, E. (2001). La pretensión de corrección del derecho. La polémica sobre la relación entre derecho y moral. Bogotá: Universidad Externado de Colombia.

9. Arango, R. (2005). El concepto de derechos sociales fundamentales. Bogotá: Universidad Externado de Colombia.

10. Atienza, M. (2001). Cuestiones judiciales. México: Fontamara.

11. Atienza, M. (2006). Derecho como argumentación. Barcelona: Ariel.

12. Austin, J. L. (1982). Cómo hacer cosas con palabras. Barcelona: Paidós.

13. Bayón, J. C. (2000). Derrotabilidad, indeterminación del derecho y positivismo jurídico. Isonomía, (13), 87-117.

14. Bernal Pulido. C. (2005). El derecho de los derechos. Bogotá: Universidad Externado de Colombia. 
15. Bernal Pulido, C. (2008). Estudio introductorio. El concepto y la naturaleza del derecho según Robert Alexy. En R. Alexy, El concepto y la naturaleza del derecho. Madrid: Marcial Pons.

16. Bix, B. (2006). Teoría del derecho: ambición y límites. Madrid: Marcial Pons.

17. Bobbio, N. (2012). Teoría general del derecho. Bogotá: Temis.

18. Bouvier, H., Gaido, P. y Sánchez, R. (2007). Estudio preliminar. Teoría del derecho y análisis conceptual. En J. Raz, R. Alexy y E. Bulygin, Una discusión sobre la teoría del derecho (págs. 9-46). Madrid: Marcial Pons.

19. Bulygin, E. (2007). Raz y la teoría del derecho. Comentarios sobre "¿Puede haber una teoría del derecho?" de Joseph Raz. En J. Raz, R, Alexy y E. Bulygin, Una discusión sobre la teoría del derecho (págs. 99-110). Madrid: Marcial Pons.

20. Bulygin, E. (2009). Mi visión de la filosofía del derecho. Doxa: Cuadernos de Filosofía del Derecho, (32), 85-90.

21. Bulygin E. y Alchourrón, C. (1991). Análisis lógico y derecho. Madrid: Centro de Estudios Constitucionales.

22. Calsamiglia, A. (1998). Postpositivismo. Doxa: Cuadernos de Filosofía del Derecho, I(21), 209-220.
23. Carnap, R. (1963). Filosofía y sintaxis lógica. México: Universidad Nacional Autónoma de México.

24. Clavijo Vergara, S. (2001). Fallos y fallas económicas de las altas cortes: el caso de Colombia 1991-2000. Revista del Banco de la República, 74(882).

25. Dworkin, R. (1986). El imperio de la justicia. Barcelona: Gedisa.

26. Dworkin, R. (2007). La justicia con toga. Madrid: Marcial Pons.

27. Faralli, C. (2007). La filosofía del derecho contemporánea. Los temas y desafíos (S. Perea Latorre, Trad.). Bogotá: Universidad Externado de Colombia.

28. Ferrajoli, L. (1995). Derecho y razón. Teoría del garantismo penal. Madrid: Trotta.

29. Ferrajoli, L. (1999). Derecho y garantías. La ley del más débil. Madrid: Trotta.

30. Ferrajoli, L. (2000). El garantismo y la filosofía del derecho (G. Pisarello, A. J. Estrada y J. M. Díaz Martín, Trads.). Bogotá: Universidad Externado de Colombia.

31. Finnis, J. (1980). Natural Law and Natural Rights. Oxford: Clarendon Press.

32. Foucault, M. (1992). El orden del discurso. Buenos Aires: Tusquets Editores. 
33. Gadamer, H. G. (2006). Verdad y método 1. Salamanca: Sígueme.

34. Gaido, P. (2011). Las pretensiones normativas del derecho. Un análisis de las concepciones de Robert Alexy y Joseph Raz. Madrid: Marcial Pons.

35. García Amado, J. A. (1992). Sobre los modos de conocer el derecho. 0 cómo construir el objeto jurídico. Droit et Societé, 20(1), 53-72.

36. García Amado, J. A. (2009). Sobre el neoconstitucionalismo y sus precursores. En Controversias constitucionales (F. Mantilla Espinosa, Trad.). Bogotá: Universidad del Rosario.

37. González Lagier, D. (2000). Los hechos bajo sospecha. Sobre la objetividad de los hechos y el razonamiento judicial. Analisi e deritto, 69-87.

38. Gracia, J., Rabossi, E., Villanueva, E. y Dascal, M. (1985). El análisis filosófico en América Latina. México: Fondo de Cultura Económica.

39. Guastini, R. (1999). Distinguiendo. Estudios de teoría y metateoría del derecho (J. Ferrer Beltrán, Trad.). Barcelona: Gedisa.

40. Guastini, R. (2008). Una teoría cognoscitiva de la interpretación. Doxa: Cuadernos de Filosofía del Derecho, (29), 15-31.
41. Habermas, J. (1998). Facticidad y validez. Madrid: Trotta.

42. Habermas, J. (2002). Verdad y justificación. Madrid: Trotta.

43. Hart, H. (1998). El concepto de derecho. Buenos Aires: Abeledo-Perrot.

44. Kant, I. (2003). Crítica de la razón pura. México: Porrúa.

45. Kaufmann, A. (1999). Filosofía del derecho (L. Villar Borda y A. M. Montoya, Trads.). Bogotá: Universidad Externado de Colombia.

46. Kelsen, H. (2002). Teoría pura del derecho (R. Vernengo, Trad.). (Segunda ed.). México: Porrúa.

47. Kelsen, H. (2005). Teoría pura del derecho. Buenos Aires: Eudeba.

48. Leiter, B. (2007). Naturalism in Legal Philosophy. En Stanford Encyclopedia of PhiIosophy. Obtenido de plato: http://plato. stanford.edu/entries/ lawphil-naturalism/ (05.05.2014).

49. Lopera Mesa, G. P. (2004). Los derechos fundamentales como mandatos de optimización. Doxa: Cuadernos de Filosofía del Derecho, (27), 211-243.

50. López Medina, D. E. (2007). El derecho de los jueces. Obligatoriedad del precedente constitucional, análisis de sentencia y lí- 
neas jurisprudenciales y teoría del derecho judicial. Bogotá: Legis.

51. López Medina, D. E. (2012). La letra y el espíritu de la ley. Reflexiones pragmáticas sobre el lenguaje del derecho y sus métodos de interpretación. Bogotá: Temis.

52. Luque Sánchez, P. y Ratti, G. (2012). Acordes y desacuerdos. Cómo y por qué los juristas discrepan. Madrid: Marcial Pons.

53. Navarro, P. y Redondo, M. C. (2002). La relevancia del derecho. Ensayos de filosofía jurídica, moral y política. Barcelona: Gedisa.

54. Nino, C. S. (1994). Derecho, moral y política. Una revisión de la teoría general del derecho. Barcelona: Ariel.

55. Nino, C. S. (2003). Introducción al análisis del derecho. Buenos Aires: Astrea.

56. Noguera Fernández, A. (2010). Los derechos sociales en las constituciones latinoamericanas. Valencia: Tirant lo Blanch.

57. Popper, K. (1974). Búsqueda sin término. Una autobiografía intelectual. Madrid: Tecnos.

58. Putnam, H. (1983). Lo analítico y lo sintético. Cuadernos de Crítica, (24).

59. Rabossi, E. (1985). El análisis filosófico en Argentina. En J. Gracia, E. Rabossi, E. Villa- nueva y E. Dascal. El análisis filosófico en América Latina. México: Fondo de Cultura Económica.

60. Raz, J. (1985). La autoridad del derecho. Ensayos sobre derecho y moral. México: Universidad Nacional Autónoma de México.

61. Raz, J. (1995). El problema de la naturaleza del derecho. Isonomía, (3), 131-151.

62. Raz, J. (2007). ¿Puede haber una teoría del derecho? En J. Raz, R. Alexy y E. Bulygin, Una discusión sobre la teoría del derecho (págs. 47-86). Madrid: Marcial Pons.

63. Raz, J., Alexy, R. y Bulygin, E. (2007). Una discusión sobre la teoría del derecho. Madrid: Marcial Pons.

64. Rorty, R. (1998). El giro lingüístico. Dificultades metafilosóficas de la filosofía lingüística. Barcelona: Paidós.

65. Rorty, R. (2001). La filosofía y el espejo de la naturaleza. Madrid: Cátedra.

66. Russell, B. (2003). Escritos filosóficos. Madrid: Alianza.

67. Sastre Ariza, S. (2001). Algunas consideraciones sobre la ciencia jurídica. Doxa: Cuadernos de Filosofía del Derecho, (24), 579-602.

68. Searle, J. (1995). La construcción de la realidad social. Barcelona: Paidós. 
69. Shapiro, S. (2007). The "Hart-Dworkin" Debate: A Short Guide for the Perplexed. Public Law and Legal Theory Working Paper Series, (77).

70. Shapiro, S. (2014). Legalidad. Madrid: Marcial Pons.

71. Strawson, P. (1997). Análisis y metafísica. Barcelona: Paidós.

72. Tontti, J. (2002). Tradición, interpretación y derecho. En La relevancia del derecho. Ensayos de filosofía jurídica, moral y política (P. Navarro y M. C. Redondo, Comps.). Barcelona: Gedisa.

73. Uprimny, R. y Rodríguez Garavito, C. (2006). Constitución y modelo económico en Colombia: hacia una discusión productiva entre economía y derecho. Debates de Coyuntura Económica, Modelo económico y constitución (62), 29-30.

74. Uprimny, R., Rodríguez, C. y García, M. (2006) ¿Justicia para todos? Sistema judicial, derechos sociales y democracia en Colombia. Bogotá: Norma.
75. Uribe, R. (2008). Ética y derecho en la posmodernidad. Revista Estudios de Derecho, LXV(145).

76. Vega, J. (2009). Las calificaciones del saber jurídico y la pretensión de racionalidad del derecho. Doxa: Cuadernos de Filosofía del Derecho, (32), 375-414.

77. Vernengo, R. (1988). Curso de teoría general del derecho. Buenos Aires: Depalma.

78. Von Wright, H. (1979). Norma y acción. Una investigación lógica. Madrid: Tecnos.

79. Von Wright, H. (2010). La diversidad de lo bueno (D. González Lagier y V. Roca, Trads.). Madrid: Marcial Pons.

80. Waldron, J. (2005). Derecho y desacuerdos. Madrid: Marcial Pons.

81. Wittgenstein, L. (1988). Investigaciones filosóficas. Barcelona: Crítica.

82. Wittgenstein, L. (1989). Tractatus LogicoPhilosophicus. Madrid: Alianza.

83. Zagrebelsky, G. (2007). El derecho dúctil. Ley, derechos, justicia (M. Gascón, Trad.). Madrid: Trotta. 